\title{
Anti-AXL Monoclonal Antibody-MMAE Conjugate
}

National Cancer Institute

\section{Source}

National Cancer Institute. Anti-AXL Monoclonal Antibody-MMAE Conjugate. NCI

Thesaurus. Code C132017.

An antibody-drug conjug ate (ADC), consisting of a human monoclonal antibody directed against AXL receptor tyrosine kinase (AXL; UFO) and conjug ated, through a proteasecleavable linker, to the cytotoxic agent monomethyl auristatin $E$ (MMAE), with potential antineoplastic activity. Upon administration, the monoclonal antibody moiety of HuMaxAXL-ADC binds to AXL, which is expressed on the surfaces of a variety of cancer cell types. Upon endocytosis and enzymatic cleavage, MMAE is released into the tumor cell cytosol, where it binds to tubulin and inhibits tubulin polymerization; this may result in G2/M phase arrest and apoptosis. AXL, a member of the TAM (TYRO3, AXL and MER) family of receptor tyrosine kinases and overexpressed by many tumor cell types, plays a key role in tumor cell proliferation, survival, invasion and metastasis; its expression is associated with drug resistance and poor prognosis. 